\title{
CERAMBYCIDAE (COLEOPTERA) DA COLÔMBIA. V. LAMIINAE COM UNHAS TARSAIS DIVERGENTES
}

\author{
Maria Helena M. Galileo ${ }^{1,3}$ \\ Ubirajara R. Martins ${ }^{2,3}$
}

\begin{abstract}
CERAMBYCIDAE (COLEOPTERA) OF COLOMBIA. V. LAMIINAE WITH DIVERGENT TARSAL CLAWS. New species described from Colombia: Amphicnaeia interrupta sp. nov., from Cauca; Adetus tayronus sp. nov., from Magdalena; A. aberrans sp. nov., from Santander; Parmenonta albosticta sp. nov., from Cundinamarca; Jamesia bella sp. nov., from Cauca. New records for nine species of Colombian Lamiinae (Apomecynini, Agapanthiini, Onciderini) are given.
\end{abstract}

KEYWORDS. Cerambycidae, Coleoptera, Colombia, new records, new species.

\section{INTRODUÇÃO}

A fauna cerambicidológica da Colômbia foi recentemente arrolada por MARTínEZ (2000) e contava com 321 gêneros e 694 espécies, números, que acreditamos, estão bem aquém da realidade em virtude da diversidade de formações florestais, habitat preferencial das espécies da família.

Baseados em material enviado para estudo por Claudia Martínez e Fernando Fernandéz, do Instituto de Investigaciones de Recursos Biológicos "Alexander von Humboldt", Villa de Leyva (IAHC), apresentamos novos registros e novas espécies de Lamiinae com garras tarsais divergentes das tribos Apomecynini, Agapanthini e Onciderini.

O material citado no texto pertence a: GMIC, Coleção Gilberto Mendoza, Santafé de Bogotá; IAHC, Instituto de Investigaciones de Recursos Biológicos "Alexander von Humboldt", Villa de Leyva; MCNZ, Museu de Ciências Naturais, Fundação Zoobotânica do Rio Grande do Sul, Porto Alegre; MZSP, Museu de Zoologia, Universidade de São Paulo, São Paulo; UNAB, Facultad Agronomica, Universidade Nacional, Bogotá.

1. Museu de Ciências Naturais, Fundação Zoobotânica do Rio Grande do Sul, Caixa Postal 1188, 90001-970 Porto Alegre, RS, Brasil.

2. Museu de Zoologia, Universidade de São Paulo, Caixa Postal 42594, 04299-970 São Paulo, SP, Brasil.

3. Bolsista do CNPq. 


\section{Apomecynini}

\section{Amphicnaeia interrupta sp. nov.}

(Fig. 1)

§. Tegumento preto. Cabeça com pubescência esbranquiçada, esparsa. Fronte com pontuação visível e eqüidistante. Olhos salientes; lobos superiores mais próximos entre si do que a largura de um lobo. Antenas atingem o ápice dos élitros na extremidade do antenômero VIII. Escapo robusto, acentuadamente intumescido. Antenômeros apicais mais avermelhados.

Pronoto densamente pontuado, com três faixas longitudinais estreitas de pubescência amarelada: uma no centro e duas laterais, pouco mais largas do que a central. Partes laterais do protórax com pubescência acinzentada, igualmente pontuadas. Escutelo revestido por pubescência amarelada.

Élitros revestidos por pubescência acastanhada com faixas longitudinais (fig. 1), estreitas, de pubescência amarelada: (1) faixa sutural no terço anterior; (2) faixa iniciada no nível do término da faixa 1, prolongada até o ápice e paralela à sutura; (3) faixa iniciada na base, mais próxima do úmero que do escutelo, prolongada até o terço anterior e terminada no mesmo nível da faixa 1 ; (4) faixa lateral sobre a declividade lateral, do terço anterior ao terço posterior; (5) faixa curta, subumeral. Élitros densamente pontuados na metade basal, com cerdas pretas, especialmente visíveis na metade apical. Face ventral revestida por pubescência esbranquiçada. Pontuação evidente nos mesepimeros, mesepisternos, região basal dos metepisternos, lados do metasterno, metacoxas e alguns pontos nos lados dos urosternitos I e II.

Dimensões, em mm (holótipo ₹). Comprimento total 4,8; protórax: comprimento 1,0, largura 1,1; comprimento do élitro 3,4; largura umeral 1,4.

Material-tipo. Holótipo $\subsetneq$, COLÔMBIA, Cauca: PNN (Parque Nacional Natural) Isla Gorgona (Alto el Mirador, $2^{\circ} 58^{\prime} \mathrm{N}, 78^{\circ} 11^{\prime} \mathrm{W}, 180 \mathrm{~m}$ ), 24.IV-9.V.2000, H. Torres col. (IAHC); parátipo §, 824.IV.2000, H. Torres col. (MZSP); parátipo $\subsetneq$, (Mancora, $2^{\circ} 58^{\prime} \mathrm{N}, 78^{\circ} 11^{\prime} \mathrm{W}, 60 \mathrm{~m}$ ), 8-24.IV.2000, H. Torres col. (MCNZ).

Discussão. Amphicnaeia interrupta e A. quinquevittata Bates, 1885 têm três faixas longitudinais de pubescência amarelada no pronoto e faixas claras, longitudinais, nos élitros. Amphicnaeia interrupta difere de A. quinquevittata por apresentar as faixas elitrais descontínuas, das quais três (sutural, basal, subumeral) ocorrem só no terço anterior e duas só na metade apical.

\section{Adetus tayronus sp. nov.}

(Fig. 2)

o. Cabeça com tegumento castanho-escuro. Fronte com pontos grandes, moderadamente densos. Lobos oculares inferiores com um terço do comprimento das genas. Antenas pretas, atingem o meio dos élitros. Antenômeros I-III e dois terços basais do IV cobertos por pubescência amarelo-esbranquiçada. Antenômeros V-XI esparsamente pubescentes. Protórax com tegumento castanho-escuro. Centro do pronoto com faixa larga, longitudinal de pubescência esparsa que contrasta com os lados do protórax e o prosterno que têm pubescência amarelada e densa. Faixa desnuda do centro do 
pronoto com pontos grandes; distância entre os pontos menor que o diâmetro de um ponto.

Élitros com tegumento avermelhado, escurecido numa faixa larga, longitudinal, dorsal, da base ao ápice (fig. 2); revestidos por pubescência branco-amarelada, mais esparsa no disco e mais concentrada ao longo da margem lateral; dois pequenos pincéis de pêlos brancos, um no nível do meio, outro, menos aparente, próximo ao ápice. Pontuação elitral, no quarto basal, perto da sutura, igual à do pronoto.

Mesosterno truncado anteriormente. Mesepimeros, lados do metasterno e lados dos dois primeiros urosternitos com pontos grandes. Metatíbias engrossadas gradualmente para o ápice.

‥ Antenas atingem o terço basal dos élitros. Metatíbias não-engrossadas.

Dimensões em $\mathrm{mm}$, respectivamente $3 / \mathrm{f}$. Comprimento total $6,3 / 7,8$; pronoto: comprimento $1,6 / 2,0$, maior largura $1,4 / 1,7$; comprimento do élitro 4,3/5,4; largura umeral $1,6 / 2,0$.

Material-tipo. Holótipo ơ, COLÔMBIA, Magdalena: PNN (Parque Nacional Natural) Tayrona Cañaveral $\left(11^{\circ} 20^{\prime} \mathrm{N}, 74^{\circ} 02^{\prime} \mathrm{W}, 30 \mathrm{~m}\right), 4-15 . X I I .2000$, R. Henriquez col., armadilha Malaise (IAHC); parátipo \&, 2-22.I.2001, R. Henriquez col., armadilha Malaise (MZSP).

Discussão. Adetus tayronus e A. irregularis Breuning, 1939 apresentam antenas bicolores, lados do protórax ocupados por larga faixa de pubescência amarelada e pincel de pêlos esbranquiçados na região centro-dorsal dos élitros. Adetus tayronus difere pela pontuação do pronoto constituída por pontos maiores e mais afastados entre si; pelos élitros mais curtos (relação comprimento/largura umeral, 2,7) e pelo quarto apical dos élitros com único pincel de pêlos brancos. Em A. irregularis, a pontuação do pronoto é mais fina e concentrada com pontos praticamente contíguos; os élitros são relativamente mais longos (comprimento/largura umeral, 3,0) e o quarto apical dos élitros, principalmente junto à sutura, com numerosos pincéis de pêlos brancos.

\section{Adetus aberrans sp. nov.}

(Fig. 3)

§ึ. Cabeça com tegumento avermelhado. Fronte revestida por pubescência esbranquiçada, com alguns pontos grandes. Lobos oculares inferiores tão longos quanto um terço do comprimento da gena. Vértice com pubescência amarelada. Antenas atingem o terço apical dos élitros. Antenômeros I-III e base do IV com tegumento avermelhado e acastanhado do ápice do IV ao XI. Antenômeros I-III e base do IV, revestidos por pubescência amarelada; V-XI castanho-avermelhados.

Protórax com pubescência predominantemente amarelada e, em algumas áreas, variegada com pubescência branca (principalmente ao nível do meio). Pontuação pronotal pouco visível, recoberta pela pilosidade. Processo prosternal com elevação transversal entre as procoxas. Mesosterno regularmente curvo para a parte anterior, com pubescência esbranquiçada. Mesepimeros e lados do metasterno pontuados.

Pubescência do quarto anterior dos élitros (fig. 3) predominantemente esbranquiçada, entremeada por alguma pubescência amarelada; terço central, no dorso, revestido por pubescência amarelada; nos lados, para trás do meio, uma área lateral de tegumento preto; no nível do quarto apical uma faixa transversal, de bordas irregulares, de pubescência branca no 
lado da margem e amarelada no lado da sutura; essa pubescência amarelada prolonga-se, pela sutura, até quase a extremidade e delimita mancha escura com o lado externo paralelo à sutura; entre a região amarelada e a margem esbranquiçada, duas pequenas manchas pretas, longitudinais e muito próximas.

Pernas com pubescência predominantemente amarelada e áreas escuras contrastantes e mais ou menos circulares. Metatíbias engrossadas. Abdômen com pubescência predominantemente amarelada. Lados dos urosternitos I e II com mancha preta, lisa e brilhante.

Dimensões, em mm, Comprimento total 7,2; pronoto: comprimento 1,8, maior largura 1,5; comprimento do élitro 5,1; largura umeral 1,9.

Material-tipo. Holótipo 3 , COLÔMBIA, Santander: Macaravita (Hacienda El Cairo), VI.1992, Corradine col. (GMIC).

Discussão. Adetus aberrans reúne alguns caracteres particulares: processo prosternal elevado transversalmente; processo mesosternal regularmente curvo; fêmures e tíbias com pequenas manchas de pubescência escura; urosternitos I e II com área lisa, desnuda e brilhante e a metade apical dos élitros com desenho característico.

\section{Parmenonta albosticta sp. nov.}

(Fig. 4)

3. Cabeça com tegumento avermelhado, mais escuro no occipício. Fronte com pubescência esbranquiçada e grosseiramente pontuada. Lobos oculares inferiores com menos de um terço do comprimento das genas. Antenas aproximam-se, mas não atingem o meio dos élitros. Antenas com tegumento avermelhado, exceto escapo e pedicelo que apresentam tegumento enegrecido.

Protórax tão longo quanto largo. Pronoto com pubescência esparsa; na metade posterior do dorso com pontos profundos, aproximados (distância entre pontos apenas maior que o diâmetro de um ponto). Partes laterais do pronoto com pontos profundos e pubescência esbranquiçada esparsa. Processo prosternal com elevação transversal. Mesosterno com tubérculo desenvolvido, fortemente declivente para a parte anterior. Metasterno reduzido. Proepimeros, mesepimeros, lados do metasterno e metepisternos com pontos grandes.

Élitros com tegumento vermelho-alaranjado no dorso; friso sutural, faixa longitudinal nos dois terços apicais sobre a curvatura lateral e extremidades (em pequena extensão) acastanhadas. Superfície esparsamente pubescente, com pequenos pincéis de pêlos brancos esparramados por toda a superfície, mas mais concentrados na metade apical. Extremidades elitrais arredondadas (fig. 4).

Pernas com tegumento castanho-avermelhado. Lados dos urosternitos com pubescência esbranquiçada e esparsa.

Dimensões em mm. Comprimento total 9,0; protórax: comprimento 2,2, maior largura 2,2; comprimento do élitro 6,4; largura umeral 2,5.

Material-tipo. Holótipo ơ, COLÔMBIA, Cundinamarca: Tena (Lag. P. Palo, provavelmente Laguna Pedro Palo, aproximadamente $04^{\circ} 39^{\prime} \mathrm{N} 74^{\circ} 22^{\prime} \mathrm{W}$ e $1380 \mathrm{~m}, 60 \mathrm{~km}$ ao ocidente de Bogotá), 25.X.1993, J. Cotes col. (UNAB).

Discussão. Parmenonta albosticta assemelha-se a P. fulvosticta Bates, 1885, mas difere pelas máculas de pubescência branca mais alongadas e hirsutas e pela pontuação 


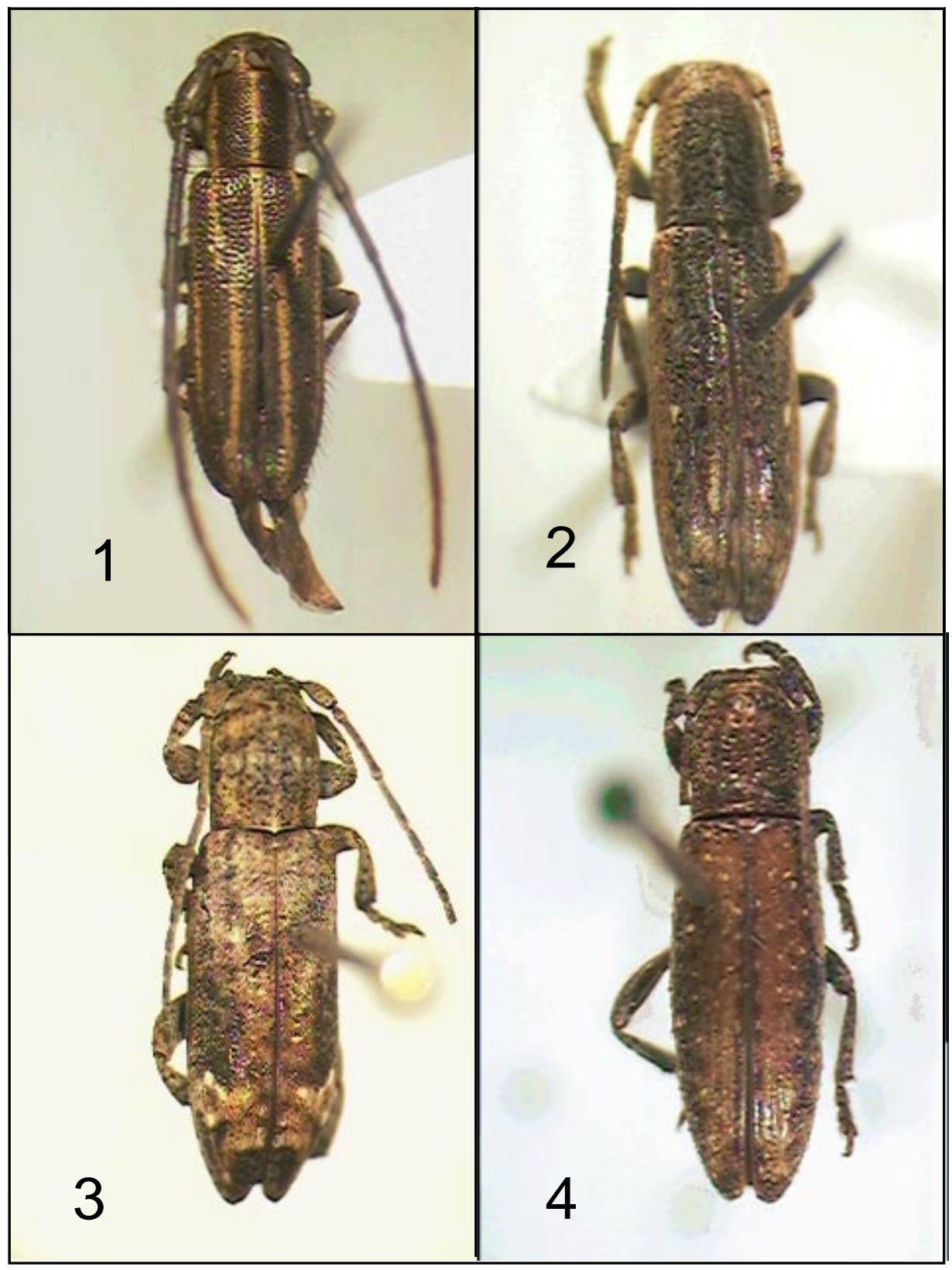

Figs. 1-4. Habitus: 1, Amphicnaeia interrupta sp. nov., holótipo $\subsetneq$, comprimento 4,8 mm; 2, Adetus tayronus sp. nov., holótipo $\sigma^{7}$, comprimento $6,3 \mathrm{~mm}$; 3 , Adetus aberrans sp. nov., holótipo ${ }^{\circ}$, comprimento 7,2 $\mathrm{mm}$; 4, Parmenonta albosticta sp. nov., holótipo $\ddot{\sigma}$, comprimento $9,2 \mathrm{~mm}$. 
elitral muito esparsa na base e inexistente no ápice. Os élitros em P. fulvosticta são "grosse (versus suturam medio lineatim) punctatis" (BATES, 1885:341).

\section{Bisaltes (Craspedocerus) ptericoptoides Breuning, 1942}

Bisaltes (Craspedocerus) ptericoptoides Breuning, 1942:141; Monné, 1994a:23 (cat.).

Originalmente descrita da Colômbia, Santa Rosa. Monné (1994a) mencionou que Santa Rosa localiza-se em Cauca.

Material examinado. COLÔMBIA, Tolima: Mariquita, ๆ, 9.VI.1972, R. Villamizar col. (IAHC).

\section{Agapanthiini}

\section{Pachypeza panamensis Giesbert, 1987}

Pachypeza panamensis Giesbert, 1987:317, fig. 3; Monné, 1994a:44 (cat.); Hovore \& Giesbert, 1998:80 (em chave).

Pachypeza panamensis foi descrita originalmente de Cerro Campana, Panamá.

Material examinado. COLÔMBIA, Santander: Macaravita (Hacienda El Cairo), ơ, 30.III.1994, Corradine col. (GMIC).

\section{Onciderini}

\section{Jamesia globifera (Fabricius, 1801)}

Lamia globifera FABRICIUS, 1801:284.

Jamesia globifera; JEKel, 1861:259; MonNÉ, 1994b:2 (cat.).

Hypsioma gemmata Blanchard, 1843:210; Dillon \& Dillon, 1945:4 (sin.).

Jamesia gemmata; BATES, 1872:201.

Hypselomus varilosus PAScoe, 1859:35; Bates, 1865:171 (sin.).

Jamesia globifera foi assinalada para a Colômbia sem que fossem citadas localidades precisas (Dillon \& Dillon, 1945). Monné (1994b) citou-a como ocorrente desde a Costa Rica até o Brasil (Amazônia) e Bolívia.

Material examinado. COLÔMBIA, Amazonas: PNN (Parque Nacional Natural) Amacayacu Matamata $\left(3^{\circ} 23^{\prime}\right.$ S, $\left.70^{\circ} 06^{\prime} \mathrm{W}, 150 \mathrm{~m}\right)$, , , 4.VIII-11.IX.2000, A. Parente col., armadilha Malaise (IAHC).

\section{Jamesia papulenta Thomson, 1868}

Jamesia papulenta Thomson, 1868:43; MonnÉ, 1994b:2 (cat.); Martínez, 2000:101

Esta espécie, cuja localidade-tipo é "Nova Granada", ocorre desde a Nicarágua até o Peru (Monné, 1994b). Martínez (2000) registrou-a para Colômbia, Vichada.

Material examinado. COLÔMBIA, Boyacá: Iguaque (La Planada, $5^{\circ} 25^{\prime} \mathrm{N}, 73^{\circ} 27^{\prime} \mathrm{W}, 2085 \mathrm{~m}$ ), †, 4-8.XII.2000, P. Reina col., armadilha Malaise (IAHC). 


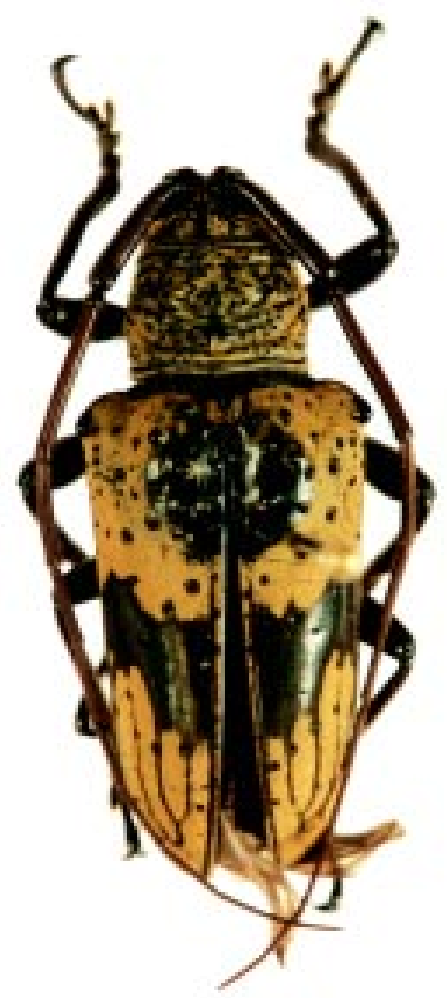

Fig. 5. Jamesia bella sp. nov., holótipo $\{$, comprimento $22,4 \mathrm{~mm}$.

\section{Jamesia bella sp. nov.}

(Fig. 5)

६. Tegumento preto; antenas e protíbias mais avermelhadas. Fronte muito estreita, com duas faixas amareladas, laterais, em toda extensão dos lobos oculares; centro com rugosidades. Lobos oculares inferiores muito desenvolvidos com o triplo do comprimento das genas. Vértice amarelado, irregularmente maculado de castanho. Tubérculos anteníferos arredondados. Antenas unicolores, sem anéis de pubescência clara; atingem as pontas dos élitros no ápice do antenômero IX. Franja de pêlos no lado interno do antenômero III densa e curta (comprimento dos pêlos subigual à largura do artículo).

Protórax revestido por pubescência amarelada entremeada, no pronoto, por numerosas manchas acastanhadas, pequenas e subcirculares. Pronoto com cinco tubérculos pequenos: dois ântero-laterais, mais aguçados; um central, mais ou menos subdividido e dois látero-posteriores; sulcos anterior e posterior bem profundos, $\mathrm{o}$ posterior desde o pronoto até as partes laterais do protórax; estas sem tubérculo.

Élitros (fig. 5) revestidos por pubescência amarelada; cada um com uma mancha preta, glabra, semicircular, logo atrás do escutelo e prolongada até o quarto anterior; uma faixa larga, com bordas irregulares, no meio, em forma de "V" invertido; essa faixa emite 
quatro prolongamentos: os dois mais próximos da sutura e os dois mais laterais fundemse e os dois ramos resultantes unem-se antes do ápice. No terço apical, faixas estreitas, pretas, ao longo da sutura e da margem. Grânulos da base grandes e pouco numerosos; tubérculo umeral manifesto. Pontos elitrais rasos, circundados por pubescência acastanhada.

Fêmures com pubescência branco-amarelada muito esparsa. Face ventral revestida por pubescência amarelada com pontos contrastantes nos mesepimeros, centro do metasterno e dos urosternitos.

Dimensões, em mm, (holótipo §). Comprimento total 22,4; protórax: comprimento 3,8, maior largura 5,8; comprimento do élitro 16,9; largura umeral 9,3.

Material-tipo. Holótipo $\subsetneq$, COLÔMBIA, Cauca: PNN (Parque Nacional Natural) Isla Gorgona (Alto el Mirador, $2^{\circ} 58^{\prime} \mathrm{N}, 78^{\circ} 11^{\prime} \mathrm{W}, 180 \mathrm{~m}$ ), 8-24.IV.2000, H. Torres col., armadilha Malaise (IAHC); parátipo $\subsetneq$ (Mancora, 60m), mesma data e mesmo coletor (MZSP).

Discussão. Jamesia bella assemelha-se a J. fuscofasciata Dillon \& Dillon, 1952, descrita de Balzapampa, Bolívar, Equador. Difere, segundo a descrição (Dillon \& Dillon, 1952): pelas antenas sem anel claro na base dos antenômeros; pela mancha preta mais anterior dos élitros que, examinada com a que lhe corresponde no outro élitro, é arredondada e glabra; pela ausência de mancha escura apical nos élitros; pela presença de linhas escuras, longitudinais, no terço apical dos élitros; pelos lobos oculares inferiores com o triplo do comprimento das genas e pelos protarsos normais.

Em J. fuscofasciata as antenas são "feebly pale annulate" (Dillon \& Dillon, 1952: 60); a faixa escura mais basal dos élitros é em forma de "V"; existe mancha escura apical; o terço apical dos élitros não tem linhas escuras; os lobos oculares inferiores têm o dobro do comprimento das genas e os protarsos são dilatados nas fêmeas.

\section{Hypsioma lyca Dillon \& Dillon, 1945}

Hypsioma lyca Dillon \& Dillon, 1945:34, est.2, fig. 10; Monné, 1994b:6 (cat.).

Hypsioma lyca foi descrita do Peru (Junin) e do Brasil (Amazonas). Monné (1994b) acrescentou o Equador, mas referenciou apenas Dillon \& Dillon (1945) que citaram Peru e Brasil.

Material examinado. COLÔMBIA, Amazonas: PNN (Parque Nacional Natural) Amacayacu Mocagua ( $\left.3^{\circ} 23^{\prime} \mathrm{S}, 70^{\circ} 06^{\prime} \mathrm{W}, 150 \mathrm{~m}\right), 2$ †, 20-27.III.2000, A. Parente col., armadilha Malaise (IAHC).

\section{Charoides pagana (Pascoe, 1859)}

Hypselomus paganus PASCOE, 1859:35.

Hypsioma pagana; THомson, 1868:51.

Charoides pagana; Dillon \& Dillon, 1945:58, est. 4, fig. 1.

Originalmente descrita do Brasil, Pará, foi assinalada por Dillon \& Dillon (1945) para a Colômbia (sem discriminação de localidade), Peru, Brasil (Amazonas) e Bolívia.

Material examinado. COLÔMBIA. Amazonas: PNN (Parque Nacional Natural) Amacayacu Matamata ( $\left.3^{\circ} 23^{\prime} \mathrm{S}, 7^{\circ} 06^{\prime} \mathrm{W}, 150 \mathrm{~m}\right),{ }^{\circ}, 2-11 . I V .2000$, A. Parente col., armadilha Malaise (IAHC). 


\section{Cipriscola fasciata (Thomson, 1860)}

Hypsioma fasciata Thomson, 1860:118.

Hypselomus crassipes BATEs, 1865:168.

Hypsioma crassipes; Thomson, 1868:51; Lacordaire, 1872:676 (sin.).

Cipriscola fasciata; Dillon \& Dillon, 1945:83, est.3, fig. 8; Monné, 1994b:11 (cat.).

Cipriscola fasciata foi citada para o Brasil (Pará, Pernambuco ao Rio Grande do Sul), Paraguai e Argentina (Monné, 1994b).

Material examinado. COLÔMBIA, Norte de Santander: Arboledas $\left(7^{\circ} 38^{\prime} 46 " \mathrm{~N}, 72^{\circ} 48^{\prime} 13^{\prime \prime} \mathrm{W}\right.$, 946 m), ơ, 9.VIII.1974, C. Carrillo col. (UNAB); Cundinamarca: Pandi ( $4^{\circ} 11^{\prime} 40^{\prime \prime} \mathrm{N}, 7^{\circ} 29^{\prime} 50^{\prime \prime} \mathrm{W}$, 1024 m), ơ, 12.X.1974, D. Moreno col. (MZSP).

\section{Trestonia confusa Dillon \& Dillon, 1946}

Trestonia confusa Dillon \& Dillon, 1946:282, est.16, fig. 11; MonNÉ, 1994b:39 (cat.). precisa).

Originalmente descrita com base em único macho da Costa Rica (sem localidade

Material examinado. COLÔMBIA, Magdalena: PNN (Parque Nacional Natural) Tayrona Cañaveral $\left(11^{\circ} 20^{\prime} \mathrm{N}, 74^{\circ} 02^{\prime} \mathrm{W}, 30 \mathrm{~m}\right)$, ơ $^{\prime}$ 19-30.IX.2000, R. Henriquez col., armadilha Malaise (IAHC); †, 2-22.I.2001, R. Henriquez col., armadilha Malaise (MZSP).

\section{Trestonia frontalis (Erichson, 1847)}

Oncideres frontalis ERICHSON, 1847:148.

Trestonia frontalis; Monné \& Fragoso, 1984:928, fig.9; Monné, 1994b:39 (cat.).

Trestonia chevrolatii BuQuet, 1859:46; Monné \& FraGoso, 1984:928 (sin.).

Monné \& Fragoso (1984) citaram T. frontalis para Peru (Junin, Loreto), Brasil (Amazonas, Pará, Rondônia, Mato Grosso) e Bolívia.

Material examinado. COLÔMBIA, Amazonas: PNN (Parque Nacional Natural) Amacayacu Mocagua ( $\left.3^{\circ} 23^{\prime} \mathrm{S}, 70^{\circ} 06^{\prime} \mathrm{W}, 150 \mathrm{~m}\right)$, f, 7-14.VIII.2000, A. Parente col., armadilha Malaise (IAHC).

Agradecimentos. A Antonio Santos Silva (MZSP) e Rafael Santos de Araujo (MCNZ) pela execução das fotografias. O material do IAHC foi colecionado com auxílio concedido a Michael Skarkey e Brian Brown pelo National Science Foundation, USA (DEP 9972024).

\section{REFERÊNCIAS BIBLIOGRÁFICAS}

Bates, H. W. 1865. Contributions to an insect fauna of the Amazon Valley. Coleoptera:Longicornes.

Ann. Mag. Nat. Hist., London, (3)16:167-182.

1872. On the longicorn Coleoptera of Chontales, Nicaragua. Trans. Entomol. Soc. London, London, 1872:163-238.

1885. Biologia Centrali-Americana. Suppl. to Longicornia. London, British Museum. v.5, p.249-436.

Blanchard, C. E. 1843. In: Voyage dans l'Amérique meridionale... par Alcide d'Orbigny. Paris. v.6, n.2, p.206-210.

Breuning, S. 1942. Novae species Cerambycidarum. XI. Folia zool. hydrobiol., Riga, 11:113-175.

Buquet, J. B. 1859. Notice monographique sur un genre nouveau de coléoptères de la famille des cérambycides (longicornes). Arcana Nat., Paris, 1:45-49. 
Dillon, L. S. \& Dillon, E. S. 1945. The tribe Onciderini Part I. Sci. Publ. Reading Publ. Mus., Reading, 5:1-186.

_. 1946. The tribe Onciderini Part II. Sci. Publ. Reading Publ. Mus., Reading, 6:189-413.

_. 1952. The tribe Onciderini. Supplementary notes. Ann. ent. Soc. Am., Washington, 45:59-79.

ERICHSON, W. F. 1847. Conspectus insectorum coleopterorum quae in Republica Peruana observata sunt. Arch. Naturgesch., Berlin, 13:67-185.

FABRICIUS, J. C. 1801. Systema eleutheratorum secundum ordines, genera, species: adiectis synonymis, locis, observationibus, descriptionibus. Kiliae. v.2, 687p.

Giesbert, E. F. 1987. The tribe Pachypezini: first Central American records, with a new species of Pachypeza from Panama. Coleop. Bull., Lawrence, 41(1):315-318.

Hovore, F. T. \& Giesbert, E. F. 1998. New species and records of Agapanthiini from Mexico and Central America. Occ. Pap. Cons. Coleop., Burbank, 2(1):77-81.

Jekel, H. 1861. Observations suggérées par les notes de M. Chevrolat sur les cérambycides de M. Thomson. J. Entomol., London, 1:255-262.

Lacordaire, J. T. 1872. Histoire naturelle des insectes. Paris, Roret. v.9, p.411-930.

Martínez, C. 2000. Escarabajos Longicornios (Coleoptera: Cerambycidae) de Colombia. Biota Colombiana, Bogotá, 1(1):76-105.

Monné, M. A. 1994a. Catalogue of the Cerambycidae (Coleoptera) of the western hemisphere. Part XIV. São Paulo, Sociedade Brasileira de Entomologia. 72p.

1994b. Catalogue of the Cerambycidae (Coleoptera) of the western hemisphere. Part XV. São Paulo, Sociedade Brasileira de Entomologia. 108p.

Monné, M. A. \& Fragoso, S. A. 1984. Notas sôbre Onciderini. Pesq. Agropec. Bras., Brasília, 19(8):925-933.

Pascoe, F. P. 1859. On some new genera and species of longicorn Coleoptera. Part IV. Trans. Entomol. Soc. London, London, (2)5:12-61.

Тномson, J. 1860. Essai d'une classification de la famille des cérambycides et materiaux pour servir a une monographie de cette famille. Paris, Société Entomologique de France. $404 \mathrm{p}$.

_._ 1868. Révision du groupe des oncidérites. Physis Rec. Hist. Nat., Paris, 2(5):41-92.

Recebido em 22.10.2002; aceito em 25.12.2002. 